INVITED 2009 SocIOLOGY Graduate Student SPONSORED LECTURE SERIES

AT THE

UNIVERSITY OF KANSAS 



\title{
INTERVIEW WITH Colin Jerolmack
}

\author{
Interview with Colin Jerolmack \\ INTERVIEW CONDUCTEd BY: \\ Rachel Craft (University of Kansas) \\ James Ordner (University of Kansas) \\ Interview Prepared By: \\ Rachel Craft (University of Kansas)
}

Colin Jerolmack is an Assistant Professor at New York University in Sociology and Environmental Studies. He is the author of The Global Pigeon (forthcoming) and an alumnus of the Robert Wood Johnson Foundation Scholars in Health Policy Program at Harvard University.

CRAFT: Colin, I would like to officially welcome you and to thank you for taking the time to interview with us today.

JEROLMACK: Sure, I'm very glad to be here.

CRAFT: I'll go ahead and start with the first question: We would like to know more about your transition from graduate student to the job market and then to a faculty position. In connection with that, do you have any advice for sociology graduate students in this dismal economy?

JEROLMACK: (laughs) It should get better. I was in some ways quite fortunate. I was hired at New York University at the same time that I got a post-doc to go to Harvard University. What that has meant in terms of my transition is that I have not had to immediately go from defending in the spring to teaching in the fall and all of the other commitments that go with being a professor. So I actually can't speak to that. I know people make that transition all the time. 
I don't know if I would have been ready for it.

One piece of advice for graduate students is this: publish, publish, publish - start work on it as early as you can. For me personally, I had kind of a strange project. I knew that in some ways I might have to be held to a higher standard than the people I was competing with because some people thought my project wasn't important. As soon as I knew what my dissertation was, I carved out pieces that I thought were amenable to being articles first. I wrote four articles before I ever wrote a chapter as a chapter, and I got them out. I always had something under review, though they were almost always getting rejected. I've only had one article that did not get rejected the first time. I had one that was rejected four times but still wound up in a very good journal in the end. That meant that even though they were getting rejected, I still got stuff sent out early so that it was percolating, and I was getting constant feedback through peer review. I actually delayed going out to the job market for a year. I felt that in my fifth year I could have gone on the job market, but I wasn't happy with my publication record. I also had some stuff under review that I was praying would get accepted — and it did. It doesn't always work out that way, and I probably still would have gone out on the market the next year even if it didn't because it would have been six years, and I felt that was enough, and I was paying to go to grad school. Thankfully, I had two of my major articles accepted and then come out during the course of my sixth year, so then when I went on the market all of a sudden I was a much stronger candidate than I was the year before because of having an article in Social Problems and an article in the American Sociological Review. That was the biggest thing. Any way that you can think of to position your research and your ideas so that you are trying to do articles early on is great.

Going on the market... it's stressful, but it can be a lot of fun if you actually get interviews. As a graduate student, often you are just so caught up in trying to do your own thing and it's hard to imagine that for two days an entire department will focus all its energy on you. I found it to be exciting. I mean, I was nervous, but it was just great. I never felt I was taken that seriously as a scholar before. The talk is really stressful, but at the same time, 
I'd never gotten forty-five minutes to talk about what I wanted to talk about. Regarding the 12-15 minute format of American Sociological Association conference presentations and those other kinds of things, I always felt if I had more time I could really get my point across; so, enjoy the job market. I had fun.

Then, I transitioned to being a post-doc. It's great-I work on my book a whole lot. The post-doc is funded by the Robert Johnson Foundation, so you're expected to do something related to health policy, and part of my project touches on our fear, response to, and surveillance of "zoonotic" diseases that can be transmitted from animals to humans. I was able to continue to work on my own project, and I didn't have to go off on a whole new tangent. If you can get a post-doc, that's great. A post-doc can also be a great way for people who don't have a lot of publications to get another year or two to work on journal articles. The transition to a job is "to be continued." I haven't got there yet, so I'll have to let you know. I'm glad I've had this nice post-doc to bridge the gap and really ease that transition.

CRAFT: You are really lucky to have the post-doc. Thank you for the advice - publish, publish, publish. It's valuable information. Moving along, I found a news article on Word Press that quoted your involvement in the freegan movement. Could you briefly describe for those who do not know what freeganism is and how involved you are or were in the movement both personally and as a researcher?

JEROLMACK: Sure. Freegan is a play on vegan. A vegan is somebody who is a strict vegetarian and uses no animal products at all - no meat, no cheese, no yogurt, no dairy, etc. I'm vegan. I've been vegan for over a decade. What happened is this: A lot of vegans are very politically active. Many of them are left-wing anarchists, Marxists, etc., so a lot of people situate being vegan within a larger project that they may be involved in, trying to be as anti-consumerist as possible. Basically, a lot of vegans said, "Fine, I don't want to be part of the system that exploits animals, but at the same time, there's all this stuff that's going to waste." A 
lot of "punk rockers" are involved in dumpster diving. You go to all these supermarkets that throw out great food - food that really has nothing wrong with it - and the stores actually put it in separate trash bags from mixed trash. Many vegans said, "Well what if I find stuff in the dumpster that's not necessarily vegan?" I mean, I'm purely vegan but I know a lot of people who will eat dairy and stuff they get from the trash because their notion is "I'm not contributing to exploitation - this is just being thrown out. I'm not buying a product that now the store's going to replace." So freeganism kind of comes out of that. It's now become a very broad term to mean anybody who's reusing things as far as I can tell.

I was involved with a collective of people in Brooklyn who were into taking old bikes, damaged bikes, any bikes that people would give us, and remaking them, rebuilding them, and making kind of freaky bikes; we would cut them up and weld them. We would have events where people could come ride our bikes. I personally didn't think of that as freeganism but, New York being New York, media was everywhere, and there were some articles written about us as freegans doing this bike thing. That's my main involvement

There was a TV show in France that did something on freegans in New York, and I was contacted by the chair of the City University of New York who wrote me "Hey, don't you do stuff where you recycle bikes or whatever? These people are looking for some people to talk to." I talked to them, and then, that lead to this article. I can't really say that I'm that involved on a day to day basis, particularly in New York, and I never researched it at all. I actually refrained. A lot of people asked, "Why don't you write about this whole bike culture in New York?" I refrained from doing that because I just wanted to do something new that didn't directly involve my personal biography.

CRAFT: It seems like a fairly good research topic. I notice there's been an influx of things like Freecycle and free for all sales.

ORDNER: I'd like to continue on with this idea of having people politically active in certain types of activities. How important 
do you think it is for sociologists to be active in social and environmental justice causes? Should we stand back, as objective analysts, and describe these problems, or should we take an ethical stance and attempt to activate change?

JEROLMACK: This is a classic question; this is a Weberian question of the fact-value separation. I'm of two minds on this because I, personally, don't see a clear divide between the two, and I often think that I'm impartial to the motivations that may bring a person to do the work that they do. If people are politically motivated by certain causes, and this is their passion, and this is why they choose the topic that they choose, I think that's great. If other people want to choose a topic because they think that it is interesting or because there is a gap in the literature, I think that's also great. At the same time, I honestly believe that if our first goal is to make a political difference, then, there are better avenues available than being a sociologist. One barrier for the politically-minded sociologist has to do with the academy's reward structure. We are rewarded for publishing empirically rigorous work that meets certain criteria that are somewhat beyond our control, such as peer review, which means that you have to default to the normative position of the discipline regardless of your normative stance. I imagine that if you are primarily motivated to make political change, you will be continually disappointed when it comes to trying to fit that project within the normative framework of the mainstream of sociology.

One of the things I see is this continual downward pressure to publish and be professionalized even earlier. Most of our advisors did not publish a paper in graduate school, but right now, you cannot get a job unless you publish in graduate school. Much earlier on we are faced with having to bend our work into what is acceptable. That's negative. On the positive side, I do believe that if you do empirically rigorous work that people who do other kinds of work can see makes a contribution, then there is a space for your work - even if the topic is unusual, like my research. With that said, I think you can still do a project that is political and has political aims, but, if it becomes a substitute for doing empirically 
rigorous work and making claims that fit the data, one will have a hard time in mainstream academia.

ORDNER: To continue on, would you consider your work to be a part of the public sociology project that's kind of hot right now?

JEROLMACK: Not yet. I mean, you know, again, I'm fortunate enough to be in the position I'm in to have a wonderful job and a wonderful post-doc, but I'm still a budding scholar at this point. I've produced a couple articles that, let's be honest, have been read by a couple of hundred people. I mean, that would be generous; many articles are read by only a few dozen people, so, I would hardly say that my empirical work is an exercise in public sociology.

One thing that's been fun, and I think some of it can come about by virtue of being in New York, is you kind of just meet people and things happen, so I wrote a couple of Op-Eds and that sort of gets you known too. I'm starting to see opportunities where I'm getting contacted for things or an opportunity comes up where I can have a voice, and I can say things that are directed at a more mainstream audience. For example, a woman was just writing an article about why we are obsessed with our pets for Forbes magazine and she contacted me. It was great because I was able to make a more general statement to a wider group of people about humananimal relationships. I'm also very hopeful about my book. I don't have any illusions that my book is going to be a best seller, but I'm writing my book in a way that my mother can read it, understand it, appreciate it, and find value in it. I'm very much trying to engage with relating this to issues about wildlife regulations in cities, addressing issues such as thinking about where we are going overboard, where we're missing the mark, and whether we can come up with more pragmatic and perhaps humane policies. My book's going to have a lot of pictures, black and white and color pictures, and I hope and plan for it to be sold in stores like Barnes and Noble and Borders.

I really think that it's hard to put yourself out there as a public figure who's going to want a lot of attention if you do not at least have a book behind you. When the book is out, then people can 
reference it. At this point, I have a couple of specialized articles in a couple of sociology journals, but there are opportunities opening up, and I'm pretty excited about them. I think books can be works of public sociology, particularly for ethnographers who tell stories and have compelling characters so that people are interested in what happens to them in places that are familiar to the reader. You can put messages in there in a broader way, and you can footnote the purely technical theoretical aspects because the sociologists who are interested in that stuff will recognize the disciplinary conversations I am in or can check out the articles I've written. I'm very excited about the opportunity to engage a wider audience, and I think books are a good way to do that.

ORDNER: Regarding your Social Problems article, ${ }^{1}$ if we are hostile to the animals that exist on this boundary where nature and culture is constructed and negotiated, what do you think this says about our attitude towards nature itself?

JEROLMACK: The roots of this article are the roots of this entire project. As you might imagine, I actually did not set out to write a dissertation about pigeons. I was interested in how people fight over public space and what they fight over. I had been doing research in lower Manhattan, particularly in certain parks that were being renovated, and when a park is renovated there's a public review; there are all these things. Here I was witnessing live moments where people are fighting over their spaces, where the past intersects with the future. People are saying, "This is the history; this was originally built as an extension of the Catholic Church, and this was the piazza, so we need to retain the Italian character." I was really interested in these intersections, this conflict, and people trying to hold on to tradition and thinking about what would serve present and future interests. A couple of the things that kept coming up again and again as problems that plagued these spaces were the homeless and the pigeons, and both were really talked about in the same way. "If we could stop the homeless from sleeping in

${ }^{1}$ Jerolmack, Colin. 2008. "How Pigeons Became Rats: The Cultural-Spatial Logic of Problem Animals." Social Problems 55(2): 72-94. 
these parks, if we could keep the pigeons from crapping on these benches, we could have some nice spaces."

There's a whole literature in urban sociology; one way of looking at it is "broken windows." There's related literature that's much older, Chicago School research about defended territories, like neighborhoods. If they are ethnically homogenous or homogenous by class, then almost any time there's an "invasion" of a different ethnic or class group, there's a fight; and the group that is present and has been there a long time will defend its territory in an almost primordial way. Gerald Suttles called these kinds of neighborhoods "defended territories," and I started to see that cities did many things to make themselves defended territories from nature. People very much came to view cities, on a broad level, in opposition to natural forces. The city is supposed to be the pinnacle where civilization has extracted itself from nature and doesn't have to deal with it at all except on our terms - pets, we declaw them, bring them into the home, domesticate them, and civilize them and they are no longer part of nature anymore. They're animals of course, but animals that can move about on their own mobility and that we can't control are often seen as antithetical to modern civilized society, so I very much see Western cities as defended territories, as trying to construct defended territories against animals.

As I try to point out in the article, there are many exceptions to this; certainly rare and majestic animals like hawks and falcons - we get very excited when they show up in the city. However, if they show up in large numbers we wouldn't be so excited anymore. It's because they are rare that their presence imparts a sense of enchantment to these urban spaces. Go to the zoo, that's fine; a couple of swans or ducks in Central Park are great; but they wouldn't be great if they were walking down the street or in our back yard. I really think on a broader level, it's sort of cliché, but I think it speaks to our alienation from nature. Pigeons cause problems; I don't deny that they cause problems. I mean, their acidic feces eat away at statues and monuments, but the disease thing is a total farce. We don't have to worry about disease almost at all unless we're in an enclosed environment breathing in aerosolized pigeon feces. That's a red herring. 
One thing that I ask is, and pigeons just happen to be the perfect example of this, is why we do not hold ourselves accountable for the roles we play in abetting "nuisance" animals. Pigeons are actually non-native to the United States and Europe. They're there because over centuries we intentionally domesticated them and bred them. The French brought pigeons to North America in the 1600s as a food source. Pigeons already had a pretty good number of clutches of eggs that they could produce per year, but we bred them to be even more fecund. We bred them to be able to exist in even harsher conditions. We made a sort of "super pigeon" because we were eating them and they were useful to us. We brought them to the United States, and that's the reason they're here, and so one thing that I think it sort of leads us to ask is, we've created this animal as literally a cultural object - it cannot exist without us. We created an animal that is "naturally" designed to be in a symbiotic relationship with people. That history is not visible. There's just sort of this annoyance. We've experimented and tinkered with the environment so much that we've forged a lot of these relationships, and they're going to continue to be there. I think it is worth it to think about, what do we owe them, if anything, because we've created them and created this relationship, and now we don't want to have to think about of any of that. I think the lack of understanding of the history of any of these so called invasive species, and why they're here and how they came to pass, speaks to how little we know about our historic relationships with nature.

I'll just say one more thing, the starlings are an interesting story. Starlings, which are one of the biggest so-called nuisance animals, swarm into massive black clouds that eat farmers' crops. They're in the United States because in the 1860s a couple of rich folks who had a little society in Central Park decided they wanted to introduce every bird species that was mentioned in a Shakespeare play into Central Park. From the several pairs that were imported into the United States in the 1860s we have the massive starling infestation that you see before you today; so, you know, these little things go a long way.

CRAFT: Wow, I guess so. I did not know that. In line with the 
same question: Do you think there is a contradiction in how we romanticize nature as an ideal so long as it remains out there? I mean, we set aside parks and preserves and things like that, and we treasure them; yet, we treat natural, or feral, wilder, creatures with disdain whenever they attempt to co-exist in our social space or when we invade their space. Whenever we go into forest area, we expect ticks, but we go to battle with them; we arm ourselves with an arsenal of chemicals and such.

JEROLMACK: In this question, you've nailed it in the way you've framed this contradiction between romanticizing nature as an ideal as long as it's out there. Sociologists have not done a great job looking at this relationship. The people who have done a great job, which I tried to highlight in my Social Problems article, are the so-called cultural geographers. Their historic inclination has been to look at physical geography and territory. However, then the problem geographers face is that as globalization occurs, these kind of geographic areas are breaking down or shifting, and cultural practices and understandings are diffusing across different boundaries; so, geographers today - it's not your grandpa's geography. I see some of them largely as sociologists; they are doing culture. They are interested in the diffusion of practices and ideas across space, and they have been doing a very systematic job of talking about how we think about nature and the zones of nature-culture encounters and our conceptions of the boundary. They very much frame it the way you just described it. We all romanticize the farm. We buy our kids little books about the farm and farm animals and all that, but it was a huge fight to get the slaughter houses and livestock out of cities, and it wasn't all health based. You can go back to some wonderful archival records where moralists claimed that fornicating and defecating animals offended the Victorian sensibilities of women and children who were going to become immoral because of witnessing this. It was very much about cleansing our urban environment, and this gets back to the point I was making about nature and the morality of protecting the border.

Sociologists are always concerned with boundary drawing. If Michèle Lamont decided to study nature, she would find nature- 
culture "boundary work" to be just as fascinating and illuminating as her work on cultural and racial boundaries. One more book I'll just point out if anybody is interested in this topic, and I think is the best one out there, is Michael Bell's book, Childerley. ${ }^{2}$ What he does is study an English rural village and how people form understandings of themselves and their community vis-à-vis nature. They see themselves as country people and want to live close to nature, but there are all these contradictions because they're not that far from London. There are farms, but there are tons of pesticides being sprayed around, and they're owned by large corporations that are absentee landlords, so, they're not really being "in nature." However, as it also points out, when are we really ever in nature? Even when we're in natural parks, there's so much staging that goes into making them look like wild spaces. What's so beautiful about that book, though, is that instead of making these broad sweeps like David Harvey's writings on neo-liberal capitalism and naturewhich is of course valuable-Bell looks at the lived experience of people who feel themselves as being out in nature and who define themselves based on this romanticized ideal; but really, in many ways, when they have to confront the aspects of nature, like pests, they are perhaps just as quick as you or I to reach for pesticide and anything else like that. It's one of my favorite books; I would recommend that to anyone interested in the topic.

CRAFT: I understand that the economy is less your focus than the role that morality plays in the construction of social problems; however, do you believe that economy plays a role in this contradiction between our romanticized ideal of nature and the nature that attempts to coexist with us until we fight it? If you do, could you briefly explain how?

JEROLMACK: Absolutely I do, and it's part of my larger project. My book is not going to center on the economy but that's part of it, particularly if you look at so-called nuisance animals. When an animal is called a nuisance animal, it is a technical classification.

${ }^{2}$ Bell, Michael M. 1994. Childerley: Nature and Morality in a Country Village. Chicago: University of Chicago Press. 
There's a variety of reasons that an animal can be called a nuisance animal. Certainly, being a non-native species is a big one. Very few native species are ever called nuisance animals, even if they're creating a nuisance. Many non-native species will be called a nuisance simply because any activity they are doing is allegedly unnatural because they're not supposed to be here. What's interesting is, when you take a historical look, you almost never see animals getting taken off the nuisance animal list; you just see more and more getting added on to the nuisance animal list.

One of the things that happens when a nuisance animal gets added to the list is that pest control companies can track and exterminate them, often without having to get a permit from the city. The city is saying, "We consider this animal a nuisance, which means that we don't care if you trap and exterminate it," so, people call the pest company. Pest companies' business, like any other company, is to convince you that you need their product. I encourage you to go to a pest company website. You will learn that all sorts of animals that you didn't really know were a problem, or considered a problem, are "actually" a major problem. They'll list all of these really scary diseases that they carry even though if you talk to an epidemiologist she'll say, "Well, most of those diseases, humans can't catch them," or "Here's what you have to do to get that disease, you literally have to grab mountains of feces and put them in your mouth." But they don't tell you that.

Economics plays a huge part, and the pest control industry has exploded in the past twenty years or so. Pigeons have been a gold mine for them. If you look around urban environments, pigeon control is ensconced in our landscape: netting that they try to tightly tuck in so you can't really see it around ledges of buildings so the birds can't get there; plastic and metal spikes on ledges; and all sorts of other things. They have every product for every kind of animal you can imagine, and a lot of them are useless. In New York City, you probably will never hear it here, but in New York and Boston they actually have these speakers that blare recordings of birds of prey screaming. The idea is that pigeons are supposed to be afraid of it, but it doesn't work. Any ornithologist or any person who hangs out and watches the birds knows it doesn't work. 
Plastic owls do not work. Plastic owls are all over ledges. Pest control companies don't care because they're making money, and, so, absolutely economics plays a huge role.

ORDNER: Now that you're almost done with the pigeons, maybe, and you are getting to the end, what does the future look like for your research? What should we expect? Where are you going from here?

JEROLMACK: Sure. I consider myself on a broad level to be an environmental sociologist and a community scholar. Actually, a lot of my work that is going to be in the book has not yet been published. Even though it's organized around animal practices, particularly pigeons, it's really about people and their communities and how their relationships with animals become a way to organize their social life and the way that they experience and interact with and alter their physical environment. One of the things I' $m$ talking about in my evening lecture tonight is actually the people I spent the most time with who I have yet to publish on: these working class men who breed and fly domesticated pigeons from their rooftops. This is an iconic New York tradition that is dying out. Many of the reasons that it's dying out have to do with larger urban processes of gentrification and literally, losing the habitat to fly pigeons because many of them rented factory rooftops that are being torn down. This is just to say that my concern with them is really about how they conceive of their little speck of the Earth and interact with it through their animals. Those are my broader interests.

Even though I know that I'm sort of seen as a human-animal scholar, it's not the primary way that I view myself. I fell into that project because it offered a unique window into these larger processes that I'm concerned with. I'm not planning on moving on to raccoons or something like that. That said, I have one new project that I've already started. It's about climate change and its impact on local communities in Alaska. I wanted to find a way to pinpoint, in a very concrete way, how people are being affected by climate change. I have an identical twin brother who is a geologist who studies earth surface dynamics, and he has been studying melting 
permafrost in the Arctic Circle. Permafrost is the frozen dirt that basically holds the tundra together. It's melting, and what happens when it melts is the banks of rivers become mud and collapse into the river, and the rivers fill up with sediment. Sinkholes also open up and swallow houses and roads. The landscape is being devastated. This particular community, or city, is only three thousand people, but it's the largest town in the Arctic Circle and a hub for all the regional villages. The more he told me about it, I just sort of thought, well, this community sounds like they're being destroyed by this.

One of the things that is happening as these rivers are filling up with sediment and such is that it's getting harder to move goods around by boat or barges - everything has to be flown in. It's expensive enough to live up there and now everything has to be flown in, and these are people who already are among the poorest in the United States. At the same time that that's happening, they live on the very edge of a very narrow peninsula where the bluffs are eroding because of melting permafrost. The peninsula is going to turn into an island. What that means is, on one side of them is the ocean but on the other side of them is a small bay where rivers empty into it. It's relatively fresh water. They're able to fish for salmon, and for almost everybody there fish is a huge part of the diet. When that peninsula pinches through, it's all going to be salt water and that will change. In the winter time the ice is not freezing over as much. They go out on snow machines and hunt seals, but people are falling through the ice now, so there's a shorter season in which they can hunt.

I decided I wanted to study how this community was adapting and being affected by what was going on, and I felt like it's a very unique opportunity to pinpoint how a specific group of people in a specific place is being affected by this very massive large-scale process we call climate change. I just did preliminary work at this point. I went up there for several weeks, right before the American Sociological Association conference in the summer, and just kind of did a community survey, talked to folks, and saw what's going on. That's what's on deck right now. I've got some ideas that I'm going to get into when I return to New York, but they're kind of vague at this point, so they're not worth discussing. All of my interests 
revolve around how communities, whether urban or rural, interact with their environment. How is the environment both enabling and constraining communities and human groups? How does it organize their everyday lives?

For anybody who's interested, there are a lot of fascinating projects being done, and environmental sociology is a hugely growing area. At New York University, I'm dually appointed in sociology and environmental studies, which is a new program that they launched. It already is one of the most popular majors at New York University, and Columbia and the New School have started one since; and that's just in New York. Environmental studies is a huge growing area. Again, going back to the job market question, there are going to be more jobs. There is going to be a need for these interdisciplinary programs to teach people who really want to get involved in making a targeted impact. This also gets back to the question of environmental justice and how your politics enter into it because for me personally, one thing I can do to probably make a more immediate change than my own research is in teaching. Next semester I'm teaching Environment and Society in the Environmental Studies Program at New York University, and these kids want to change the world. These people are doing sustainability projects and the like, and many of them are going off to work in non-profits or start their own. In our $\mathrm{PhD}$ programs we are still emphasizing the research, and that's what gets us a job; however, I think really, in a lot of ways, that teaching is the way that we are going to make more of a difference, to be honest, for most of us. Every once in a while there will be the rare breakthrough public sociologist and book, but in every class there may be dozens or even hundreds of people, and maybe up to a quarter or a third of them will be inspired and will want to organize their career and their lives around making a difference in social and environmental justice issues. I actually think that's the way, maybe more than our research, that we can make some of the changes we want to see; and the environment is the issue, so I think there are a lot of opportunities for projects. I think sociology departments are going to be excited to hire environmental sociologists. It's not going to be as marginal as it was ten years ago. 
There's one book that I just want to mention because I see it as potentially paradigmatic in this regard. It's Javier Auyero's new book with Débora Swistun called Flammable, ${ }^{3}$ in which they did an ethnography of a shanty town outside of Buenos Aires, Argentina where Shell oil refineries and several other refineries have been operating and slowly poisoning the neighborhood with lead and all these other toxic chemicals. It's a phenomenal book, I think, because on the one hand it documents "environmental racism," if you want to call it that, and the way that these larger political and structural forces are affecting this community. On the other hand, it offers a very, very grounded clear understanding of these peoples' lived experiences of being in a poisonous environment. It also poignantly answers some fundamental questions like why are some of them so apathetic about it when the evidence is so damning and experts come in, test people, and say they have extraordinary high levels of lead and it obviously comes from this environment? Why do people fail to mobilize when they are literally being poisoned to death? It highlights important environmental justice problems that are only being exacerbated in an era where multinational companies relocate to poor countries with lax environmental regulation. It also provides a way forward for people who want to think about how we can study these very complex issues.

CRAFT: That is very interesting. I've noticed the burgeoning movement within sociology to take the environmental turn. I am kind of curious, obviously we haven't read your upcoming book yet, but whenever you talk about photographs in your book, are these photographs of pigeons and the methods of controlling them?

JEROLMACK: They're mostly photographs of people and pigeons. How many research sites do I have in my research project? They include Brooklyn, Queens, the Bronx, Chicago, London, Venice, Pretoria, South Africa and Berlin, Germany. London and Venice both, in Piazza San Marco and Trafalgar Square, had this history of feeding pigeons. There were even vendors who would

${ }^{3}$ Auyero, Javier and Débora Alejandra Swistun. 2010. Flammable: Environmental Suffering in an Argentine Shantytown. New York: Oxford University Press. 
sell feed, and people would come, and it became a huge tourist event. Both of these cities have since outlawed pigeon feeding, and it is very much in this rhetoric that I talked about in the Social Problems article about orderliness and cleanliness and reclaiming these as human spaces. Photographs that I took for that research are sort of the actual physical layout of these spaces, and some of them pertain to the devices that they're using to stop pigeons from coming. For example, In Trafalgar Square there is a man who stands in the square, who is paid 90 pounds an hour, and there is actually a trained hawk on his arm. If the pigeons came, he'd release the hawk and the hawk goes and attacks the pigeons. There are pictures of him; there are pictures of tourists looking at him. The pigeons in the space are so adapted to obtaining food from people that they've basically been trained to land on people. They're still doing it even though their legal food source has been taken away; anybody who comes into this space with bread, they land on, so there are a lot of pictures of people with pigeons landing on them.

That said, a lot of my chapters, like my ASR article, are about people who have organized their lives around animal practices, the way that anybody might with dog racing or horse shows. I already mentioned these guys in New York City who are breeding these pigeons on their rooftops. I use any kind of pictures that capture the interactions I am describing. How do they train the birds? They have these long bamboo poles that they wave that frighten the pigeons to fly higher. I have pictures of them waving the bamboo pole. I have tons of portrait pictures because this book is about people and their social relationship with animals.

What I was actually very excited about was my American Sociological Review article, ${ }^{4}$ which talks about these Turkish immigrants who were keeping pigeons in Berlin. The journal let me have pictures; there are four pictures in this article. Normally, when you open American Sociological Review, there are only charts and graphs and whatever. One of the pictures that I am really happy about in there is of a guy I'm talking to who says, "When I'm with my birds it's as if I' $m$ in nature; even though I' $m$ in the middle of a

${ }^{4}$ Jerolmack, Colin. 2007. "Animal Archeology: Domestic Pigeons and the NatureCulture Dialectic.” Qualitative Sociology Review 3(1): 74-95. 
concrete jungle I don't see the buildings around me." In the picture he is staring directly at a tamed pigeon on his hands with its wings out and you see a huge concrete building behind him that he is not paying attention to. It captures the interaction perfectly.

It's probably by virtue of being Mitchell Duneier's student, but I am very concerned with showing the people and their lives; and this includes physically showing them with pictures, but also, I don't use pseudonyms; I use real names. There's only one person in my entire history of doing research in all these places that has not wanted his name to be used. I understand there are reasons not to, but my personal belief is that the default setting should be to use the people's names in telling their stories unless they ask you not to, or unless you know something they don't about real harm that could come to them. You get to know these characters; it's not just showing you their interactions so that I can make a theoretical point about human animal interactions. I value, in and of themselves, these people's lives and their stories; and you need to do that to really understand why someone would be so passionate about breeding these animals and spending hours a day, and maybe all of their disposable income, doing so. If I was just concerned with making theoretical points then you would miss all of that. It's that sensual experience of the human-animal bond as well as the everyday ways that these guys in New York can escape to their coop. It's like their safe space that they built. If you don't feel that experience then you really don't understand their world at all. Pictures are just an element that allows me to add a little bit more of that.

One thing I did a little bit of, that I would like to do more of in future projects, is, anybody that I've taken pictures of I give them pictures. By the way, if you're an ethnographer, people love getting pictures even though now with digital cameras they could just take their own; but trust me, if you physically print out pictures and give them to your participants while they're doing the things you are researching, even if they're wealthy or whatever, they have been very excited. Douglas Harper emphasizes as a method what he calls "photo elicitation." You bring the pictures back to your participants and now it becomes a means by which you can 
have a casual interview with them about what they're doing and what they think is the significance of the picture. Sometimes they say, "Well, actually you're using the picture for this but that's not important. See, what I normally do is this, so here's what you should take a picture of." You learn by doing that, in a very grounded way, what matters to them and how they're organizing their lives. Pictures become a really nice way that, in the process of doing the research, you can get feedback around it. I think it's great for your participants to go back and read your stuff, but, to be honest, when it comes to making a sociological point, a lot of them are really not that interested at all. I found that when you have the pictures, you have something very grounded you can talk about and that they are really interested in talking about, and then, they can tell me how off the mark I am, like, "Why did you spend all your time taking pictures of this when really you should have been taking pictures of that."

In terms of moving forward ethnography, I think you're going to have to create a defense for why you are not taking pictures, or using digital recording devices in the future. There are some reasons not to. I understand particularly vulnerable populations, but overall, the technology is so easy and it's relatively cheap. These types of technologies are going to become the norm for people doing ethnography, and I think it's a good thing.

CRAFT: That's wonderful. We certainly look forward to reading your book. What's the name of your upcoming book?

\section{JEROLMACK: The Global Pigeon}

CRAFT: And this should be available this year? Next year?

JEROLMACK: (laughs) No, these things take a long time. I am still revising the manuscript, and then once I finish doing that, it needs to go back to the editor and reviewers of Chicago Press. Then, they are going to give me comments, and I am going to have to fix it. From the time that the final product is done it's about ten months lag, so 2012 is probably going to be when it comes out. 
It's not the same turnaround time we're talking about with trade publications, unfortunately, so 2012 I hope, but there will be a couple articles along the way that will give a bit more idea of what the larger project is about.

ORDNER: Very cool.

CRAFT: That is great. Thank you so much for taking the time to allow us to interview with you and get to know you and your work better, and, I suppose, that would formally conclude the interview. 